\title{
Praticando a Interdisciplinaridade No Ensino de Geografia Por Meio Das Tiras Em Quadrinhos e Cartuns
}

\author{
Practicing Interdisciplinarity in Geography Teaching Through Comic Strips And \\ Cartoons
}

\author{
Practicando La Interdisciplinariedad Em La Enseñanza De La Geografía Por Medio \\ De Las Tiras Cómicas Y Cartones
}

\author{
Vitor Ferreira de Souza ${ }^{1}$ \\ Drielle Caroline Izaias Juvino Souza ${ }^{2}$
}

Recebido em 05/07/2016. Aceito em 15/05/2017.

\begin{abstract}
RESUMO: Charges, cartuns e tiras em quadrinhos são alguns recursos didáticos que podem contribuir diretamente para o processo de ensino-aprendizagem no ensino de geografia, pois focalizam temas inerentes da ciência geográfica para compreensão do contexto socioambiental das diferentes escalas (local, regional, nacional e global) do planeta. Nesta perspectiva, o presente artigo traz reflexões de uma prática pedagógica realizada em uma escola municipal de São José do Rio Preto, no Estado de São Paulo, com dois 9o anos utilizando tiras em quadrinhos e cartuns com o intuito de potencializar a internalização de determinados conteúdos trabalhados em sala de aula. Durante a realização prática buscou-se dialogar com a disciplina de língua portuguesa, trazendo como foco dessa parceria a busca pela interdisciplinaridade, que trouxe desafios profícuos para a concretização da prática ao longo do caminho.
\end{abstract}

PALAVRAS-CHAVE: Ensino de geografia. Ensino de Língua Portuguesa. Prática pedagógica. Interdisciplinaridade.

ABSTRACT: Charges, cartoons and comic strips are some teaching resources that can contribute directly to the teaching-learning process in geography teaching as they focus inherent themes of geographical science for understanding the environmental context of different scales (local, regional, national and global ) on the planet. In this perspective, this article brings reflections of a pedagogical practice held in a municipal school of São José do Rio Preto , in São Paulo, with two 9th grades using comic strips and cartoons in order to enhance the internalization of certain content worked in the classroom . During the practical realization sought to dialogue with the Portuguese subject, bringing the focus of this partnership the quest for interdisciplinarity, which brought fruitful challenges to the achievement of the practice along the way.

KEYWORDS: Geography teaching. Portuguese teaching. Pedagogical practice. Interdusciplinarity.

RESUMEN: Charges, cartones y tiras cómicas son algunos recursos didácticos que pueden contribuir directamente al proceso de enseñanza-aprendizaje en la enseñanza de geografía, pues enfocan temas inherentes de la ciencia geográfica para comprender el contexto socioambiental de las diferentes escalas (local, regional, nacional y global) del planeta. En esta perspectiva, el presente artículo trae reflexiones de una práctica pedagógica realizada en una escuela municipal de São José do Rio Preto, en el Estado de São Paulo, Con dos o nueve años utilizando tiras cómicas y cartones

Geografia (Londrina) v. 26. nº. 2. p. $128-144$, jul/dez, 2017. 
Praticando a Interdisciplinaridade no Ensino de Geografia por Meio das Tiras em Quadrinhos...

con el propósito de potenciar la internalización de determinados contenidos trabajados en el aula. Durante la realización práctica se buscó dialogar con la disciplina de lengua portuguesa, trayendo como foco de esa asociación la búsqueda por la interdisciplinaridad, que trae desafíos provechosos para la concreción de la práctica a lo largo del camino

PALABRAS CLAVE: Enseñanza de geografía. Enseñanza de Lengua Portuguesa. Práctica pedagógica. Interdisciplinariedad.

\section{INTRODUÇÃO}

A era da informação é marcada por uma profusão de ideias e novos recursos didáticos que podem contribuir para o processo de ensino-aprendizagem da geografia escolar e de outras disciplinas.

Charges, cartuns e tiras em quadrinhos são alguns dos muitos recursos didáticos que dão suporte ao ensino de geografia, pois, muitas vezes, focalizam temas inerentes à ciência geográfica para compreensão do contexto socioambiental das diferentes escalas (local, regional, nacional e global) do planeta.

Para o ensino de geografia, o seu uso nas escolas pode representar uma inovação frente às dificuldades no processo de ensino-aprendizagem, oportunizando um distanciamento de uma abordagem meramente descritiva, que não apresenta reflexão crítica e contextual do tema.

Além disso, o uso dos quadrinhos, cartuns e charges pode contribuir para romper com a fragmentação das disciplinas e do conhecimento, podendo gerar trabalhos interdisciplinares entre as mais diferentes disciplinas escolares.

A associação com o conteúdo didático de Língua Portuguesa torna-se inevitável, uma vez que o uso destes gêneros textuais demandam dos alunos certas competências leitoras, contribuindo para o exercício da leitura crítica e reflexiva a partir de temas que oportunizam o conhecimento da realidade que os cerca.

Nesta perspectiva, o presente artigo traz reflexões de uma prática pedagógica com dois 9o anos de uma Escola Municipal de São José do Rio Preto, no Estado de São Paulo, utilizando cartuns e tiras em quadrinhos no ensino de geografia e língua portuguesa.

\section{A BUSCA POR NOVAS LINGUAGENS PARA O APRENDIZADO}

O interesse em se trabalhar com tiras em quadrinhos, cartuns e charges surgiu a partir de uma leitura do artigo da Silva e Cavalcanti (2008) publicado na revista Boletim Goiano de Geografia, intitulado "A mediação do ensino-aprendizagem de geografia, por charges, cartuns e tiras em quadrinhos", que aborda as contribuições desses gêneros para aprofundar temas importantes do ensino de geografia e despertar o interesse dos alunos. 
Para Silva e Cavalcanti (2008, p.143), o uso dessa linguagem pode ser "[...] instigante, criativo, crítico, questionador, podendo com humor e aprofundamento científico servir a propósitos didático-pedagógicos". As autoras ressaltam que o trabalho em sala de aula com esses recursos didáticos podem tornar a aula "[...] mais receptiva e agradável e, principalmente, estimula uma leitura mais apurada da realidade vivida e da desmistificação da ideologia que permeia as relações sociais e políticas do mundo" (SILVA, CAVALCANTI, 2008, 144).

As tiras em quadrinhos, charges e cartuns possuem diferenciações sutis quanto aos seus significados. Para Mendonça (2001, p.198):

As tiras são um subtipo de $\mathrm{HQ}$; mais curtas (até 4 quadrinhos) e, portanto, de caráter sintético, podem ser sequenciais ("capítulos" de narrativas maiores) ou fechadas (um episódio por dia). Quanto às temáticas, algumas tiras satirizam aspectos econômicos e políticos do país, embora não sejam tão "datadas" como a charge. Dividimos as tiras fechadas em dois subtipos: a) tiras piada, em que o humor é obtido por meio das estratégias discursivas utilizadas nas piadas de um modo geral, como a dupla possibilidade de interpretação, sendo selecionada pelo autor a menos provável; b) tirasepisódio, as quais o humor é baseado especificamente no desenvolvimento da temática numa determinada situação, de modo a realçar as características das personagens.

As tiras em quadrinhos possuem balões, quadros e são narrativas sequenciais, sendo que "[...] a história pode se desenvolver numa tira, numa página ou em duas ou em várias páginas (revista ou álbum)" (MORETTI, 2016, p.2). O cartum e a charge, no entanto, não apresentam uma sequência. São desenhos humorísticos que costumam ter por temas acontecimentos da atualidade, podendo conter ou não balões ou legendas. Segundo Moretti (2016, p.2), a charge é sempre representada com caricaturas, já o cartum é criação do autor, sendo "[...] universal, atemporal e não-perecível”.

Como cartuns, charges e tiras em quadrinhos podem ser trabalhados de múltiplas formas, é possível unir as disciplinas escolares a partir desse recurso didático abordando diferentes conteúdos e habilidades. Essas linguagens podem representar uma mudança frente aos métodos tradicionais de ensino que priorizam, sobretudo, a memorização dos conteúdos, negligenciando uma reflexão crítica e contextual dos temas trabalhados. Nesse sentido, o seu uso pode permitir caminhos para se traçar um trabalho interdisciplinar.

Neste ponto, Morin (2014, p.16) traz contribuições profícuas a respeito dos métodos educativos. Em seu livro "A cabeça bem-feita: repensar a reforma, reformar o pensamento", o autor ressalta que informação não é conhecimento, já que as "[...] informações constituem parcelas dispersas de saber. Em toda parte, nas ciências como nas mídias, estamos afogados de informações".

Para Morin (2014, p.16), o conhecimento só passa a ser conhecimento enquanto "organização, relacionado com as informações e inserido no contexto destas". O autor Geografia (Londrina) v. 26. nº. 2. p. $128-144$, jul/dez, 2017. 
Praticando a Interdisciplinaridade no Ensino de Geografia por Meio das Tiras em Quadrinhos...

expande seus conhecimentos e ressalta os efeitos da compartimentação dos saberes e da incapacidade que hoje em dia temos de articulá-los, uns com os outros. Sendo que a "aptidão para contextualizar e integrar é uma qualidade fundamental da mente humana, que precisa ser desenvolvida, e não atrofiada" (MORIN, 2014, p.16).

Pensando à luz das ideias do autor, as charges, os quadrinhos e cartuns podem ser ferramentas poderosas para contextualizar e integrar as mais diversas informações, já que esses recursos didáticos já são inerentemente contextualizados com as informações cotidianas.

No caso do ensino de geografia, o seu objetivo é parecido com os apontamentos realizados, já que o papel dessa área do conhecimento "[...] é refletir, compreender, observar, interpretar e saber pensar o espaço geográfico, que é um produto histórico, que revela as práticas sociais das pessoas que nele convivem" (PUNTEL, 2007, p. 285). Além de que o espaço geográfico pode "[...] ser lido e entendido de diferentes formas." (PUNTEL, 2007, p. 285).

Já para a Língua Portuguesa, os quadrinhos, charges e cartuns contribuem para dinamizar as aulas, fugindo das abordagens tradicionais que priorizam o ensino gramatical. Além disso, o trabalho com essas tipologias textuais oportunizam a leitura e interpretação de textos verbais e não verbais.

Segundo Silva (2016), a leitura e interpretação de textos verbais e não verbais por meio de charges incentivam a formação de "melhores leitores" ao passo que despertam o interesse para o hábito de ler/escrever e auxiliam no desenvolvimento de uma visão crítica do meio. Para a autora:

\begin{abstract}
A simpatia dos alunos para com os textos "visuais" é inevitável, pois parece que a charge desperta ou possui atrativos a mais do que os da linguagem estritamente verbal; mas esta relação por vezes é dificultada pelas experiências de mundo que cada um traz ou não consigo. Para alguns ela traz o novo, para outros faz parte de suas condições de produção. $O$ trabalho em sala de aula pode ser tão completo quanto aquele em que se utiliza somente o texto escrito (tradicional). (SILVA, 2016, p.10)
\end{abstract}

Dessa maneira, o ensino de geografia e o de língua portuguesa podem utilizar o recurso didático para chegar a uma mesma finalidade: transformar os alunos em "leitores do mundo", despertando uma visão crítica para além do texto, interpretando a realidade que os cerca e as diferentes imagens produzidas pela sociedade, além de objetivos específicos de cada disciplina como o trabalho linguístico de análise e interpretação de textos na língua portuguesa e a reflexão crítica e contextual a respeito de temas relacionados ao espaço geográfico no ensino de geografia.

Geografia (Londrina) v. 26. nº. 2. p. $128-144$, jul/dez, 2017. 


\section{O DESAFIO DA INTERDISCIPLINARIDADE NO ENSINO ESCOLAR}

Uma questão que surge para por em prática o trabalho apresentado é como utilizar as tiras em quadrinhos, cartuns e charges para dialogar com as outras disciplinas escolares, convergindo para o caminho da interdisciplinaridade.

Mesmo a palavra interdisciplinaridade sendo uma constante nos artigos científicos sobre educação, a sua prática nas escolas e salas de aula ainda permanece com dificuldades de consolidação.

Para Kleiman e Moraes (2002, p.24), os professores se sentem inseguros com a interdisciplinaridade, já que eles não conseguem "[...] pensar interdisciplinarmente porque toda a sua aprendizagem realizou-se dentro de um currículo compartimentado".

Professores devem ter em mente que nenhuma disciplina escolar é completa. Todas elas precisam umas das outras, por isso é necessário às disciplinas escolares estarem sempre abertas ao diálogo, procurando construir os conteúdos em conjunto. Assim como os professores constroem conhecimento com os alunos, as disciplinas devem construir 0 caminho do conhecimento juntas, pois "a interdisciplinaridade caracteriza-se pela intensidade das trocas entre os especialistas e pelo grau de interação real das disciplinas no interior de um mesmo projeto de pesquisa" (JAPIASSU, 1976, p.74).

A abertura, portanto, é necessária. O olhar de alguém de fora da disciplina pode resolver "[...] um problema cuja solução era invisível dentro da disciplina. O olhar ingênuo [...] pode, em geral erradamente, mas às vezes com acerto, permitir-se essa visão" (MORIN, 2014, p.106).

É importante salientar que essa mudança vem ocorrendo lentamente e com dificuldade, pois somos fruto de um legado do pensamento cartesiano que vigorou séculos na ciência e nas escolas. Nosso conhecimento "engavetado" acaba tornando-se desconexo com as múltiplas realidades com que nos deparamos. (MORIN, 2014).

Para Fazenda (2008, p.39):

A superação da fragmentação da prática da escola só se tornará possível se ela se tornar o lugar de um projeto educacional entendido como o conjunto articulado de propostas e planos de ação com finalidades baseadas em valores previamente explicitados e assumidos, ou seja, de propostas e planos fundados numa intencionalidade. Por intencionalidade está se entendendo a força norteadora da organização e do funcionamento da escola provindo dos objetivos preestabelecidos.

De acordo com Santomé (1998, p.66), a interdisciplinaridade é “[...] um objetivo nunca completamente alcançado e por isso deve ser permanentemente buscado. Não é 
Praticando a Interdisciplinaridade no Ensino de Geografia por Meio das Tiras em Quadrinhos...

apenas uma proposta teórica, mas sobretudo uma prática". Sendo assim, o autor ressalta que "[...] sua perfectibilidade é realizada na prática; na medida em que são feitas experiências reais de trabalho em equipe, exercitam-se suas possibilidades, problemas e limitações".

Nesta perspectiva, podemos compreender que os professores que buscam a interdisciplinaridade em suas salas de aula, assim como todos que fazem parte da escola, possuem um longo caminho a percorrer. Esse desafio é constante e as tentativas de práticas interdisciplinares são sempre profícuas no ensino como um todo.

\section{A INTERDISCIPLINARIDADE E O DESAFIO DA PRÁTICA PEDAGÓGICA}

O trabalho com as tiras em quadrinhos e cartuns foi realizado com dois $9^{\circ}$ anos em uma escola Municipal de São José do Rio Preto, cujo processo de aplicação foi dividido em cinco etapas.

Em todas as etapas do processo da atividade proposta pelo o ensino de língua portuguesa e geografia foram planejadas possibilidades de diálogo entre as duas disciplinas para que o trabalho pudesse almejar ao máximo uma prática interdisciplinar. Sabemos que a interdisciplinaridade ainda é um processo longo para se chegar a sua totalidade, assim como Santomé (1998) já nos elucidou anteriormente.

Inicialmente, o anseio de trabalhar em conjunto surgiu da necessidade de desenvolver determinadas competências leitoras com os alunos, pois percebemos que muitos não eram leitores de textos que levassem a um pensamento crítico e reflexivo de temas atuais, importantes na disciplina de geografia.

Grande parte dos alunos não lê textos jornalísticos ou revistas que tratem assuntos relevantes para o ensino de geografia. Isso faz com que haja uma lacuna no processo de aprendizagem, pois somente os conteúdos trabalhados em sala de aula não são suficientes para os alunos compreenderem o mundo que os cerca. É preciso a prática constante da leitura a fim de adquirir conhecimento de mundo e compreender a realidade em que estão inseridos.

Dessa forma, o diálogo entre língua portuguesa e geografia teve como principal foco a competência leitora dos alunos em interpretar o espaço geográfico a partir da escrita produzida por eles (resumo do texto jornalístico e interpretação da charge), do desenho (confecção da charge) e das discussões que surgiram ao longo de todo o processo.

A primeira etapa consistiu com a exposição dos conteúdos previamente trabalhados no ensino de geografia, entre eles: aquecimento global, cujo debate em sala de aula foi importante para os alunos compreenderem os dois lados deste discurso, já que a comunidade científica é dividida entre aqueles que acreditam na influência antrópica no 
aquecimento terrestre e aqueles que refutam esta ideia; desigualdade social; política e a educação no mundo.

$\mathrm{Na}$ segunda etapa, foram dados aos alunos diversos cartuns e tiras em quadrinhos e pedido a eles que escolhessem algum deles para reproduzir na cartolina. Os alunos poderiam fazer uma releitura da tira em quadrinho ou cartum escolhido, podendo adaptá-lo à sua realidade.

Os alunos nos surpreenderam com os desenhos dos cartuns e das tiras em quadrinhos, pois ficaram muito parecidos com os originais, porém esperávamos que eles fossem mais criativos em modificar as tiras e os cartuns, adaptando ao seu contexto de vida.

Com os conteúdos previamente trabalhados no ensino de geografia e as tiras e cartuns confeccionados na cartolina, avançamos para a terceira e quarta etapas com a disciplina de Língua Portuguesa. Foram trabalhados alguns textos expositivos que contemplassem os temas previamente abordados em geografia (aquecimento global, desigualdade social, política e educação no mundo). Esta etapa foi necessária para os alunos observarem como as temáticas abordadas na aula de geografia circulam pelo mundo e de que maneira essas informações são veiculadas para o público em geral.

Nessa etapa, os alunos puderam compreender que os conteúdos trabalhados no ensino de geografia estão cotidianamente na mídia e devem ser compreendidos a partir de uma reflexão crítica por parte deles. Com o auxílio da disciplina de língua portuguesa, eles puderam ler e compreender os significados das palavras e a intencionalidade dos autores com maior profundidade, já que são habilidades específicas dessa matéria.

Após a leitura dos textos jornalísticos, iniciamos a quarta etapa, que constituía na realização de um resumo da notícia (figura 01) a fim de ativar as estratégias de leitura previamente trabalhadas em língua portuguesa, além de exercitar as habilidades de compreensão e síntese textual. Podemos afirmar que esta etapa também permitiu que os alunos adquirissem mais insumos para interpretar os cartuns, charges e quadrinhos.

O resumo dos textos foi um processo profícuo para os alunos, conferindo mais autonomia para a interpretação das charges, tiras e cartuns, pois a partir do resumo possuíam um referencial sobre o tema produzido por eles mesmos.

A última etapa do trabalho constituiu na interpretação dos cartuns, charges e tiras em quadrinhos feitos pelos alunos.

Segundo os estudos de Gagné, Yekovich e Yekovich (1993 apud BRIDON, 2013), há quatro níveis de compreensão leitora, subdivididos em duas categorias: shallow processing, que engloba a decodificação e a compreensão literal, e deep processing, que diz respeito à inferência e ao monitoramento, ou seja, à capacidade de "embrenhar-se nos emaranhados do texto, de formar novos conceitos e posicionar-se perante o texto" (BRIDON, 2013). 
Praticando a Interdisciplinaridade no Ensino de Geografia por Meio das Tiras em Quadrinhos...

Nossa intenção era que os alunos fizessem mais que uma leitura superficial, encaixando-se no dos últimos níveis de compreensão leitora (deep processing), sendo capazes de fazer relações com os conteúdos abordados, com o conhecimento de mundo e de criar hipóteses a partir das tiras, cartuns e charges.

Figura 01 - Resumo do texto jornalístico

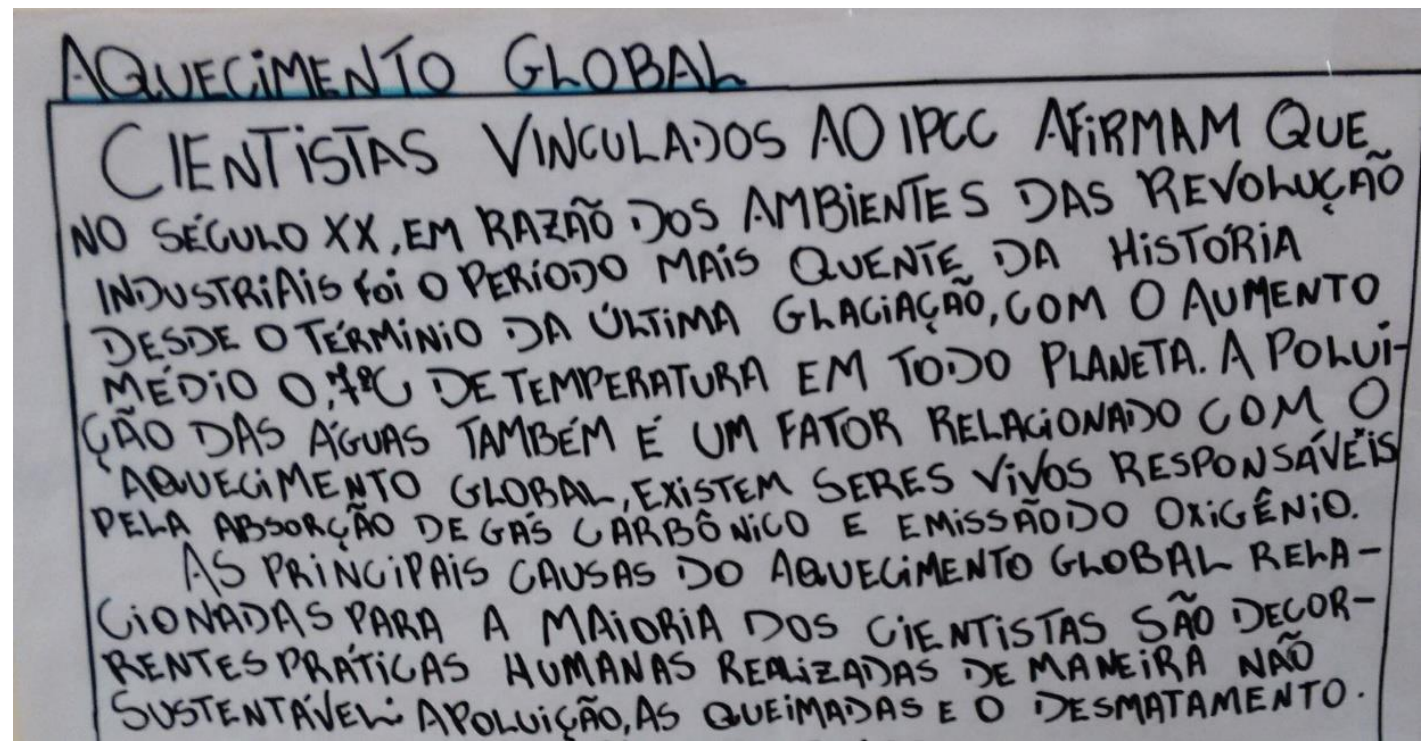

Fonte: acervo do autor

Na primeira tira (figura 02), o tema é a influência da política na educação brasileira. A tira reflete a educação brasileira nos dias atuais, já que o incentivo na área educacional no Brasil ainda é precário, mesmo com os avanços dos últimos anos. Uma pesquisa divulgada em 2012 pelo Indicador de Alfabetismo Funcional (INAF), divulgada pelo Instituto Paulo Montenegro (IPM) e pela ONG Ação Educativa demonstra que 38\% dos estudantes no nível superior não dominam habilidades básicas de escrita e de leitura (IPM, 2016). Isso aponta para uma precariedade do ensino brasileiro presente em todas as suas instâncias, não apenas na educação básica.

Para os alunos, a tira pode ser interpretada:

A política tem vários significados. Um deles é o ato de governar [...] Quem administra o dinheiro dos nossos impostos são os políticos, escolhido por todos nós. O que mais acontece é que os políticos não investem na educação, o dinheiro das pessoas é desviado.

A interpretação do primeiro cartaz (figura 02) realizada pelos alunos traz a noção da política a partir da ideia de região, pois de acordo com Corrêa (2001, p.183) a origem etimológica do termo estaria ligada ao ato de governar, ao qual se referia "à unidade político-territorial em que se dividia o Império Romano". Além disso, demonstra-se uma 
consciência política dos alunos, pois citam o problema dos impostos desviados que a sociedade paga que poderia ser investidos na educação.

O cenário da educação brasileira apontada se reflete no segundo cartaz (figura 03) que aborda a crise da educação nas escolas públicas de nível médio.

Figura 02 - Confecção dos cartazes feita pelos alunos

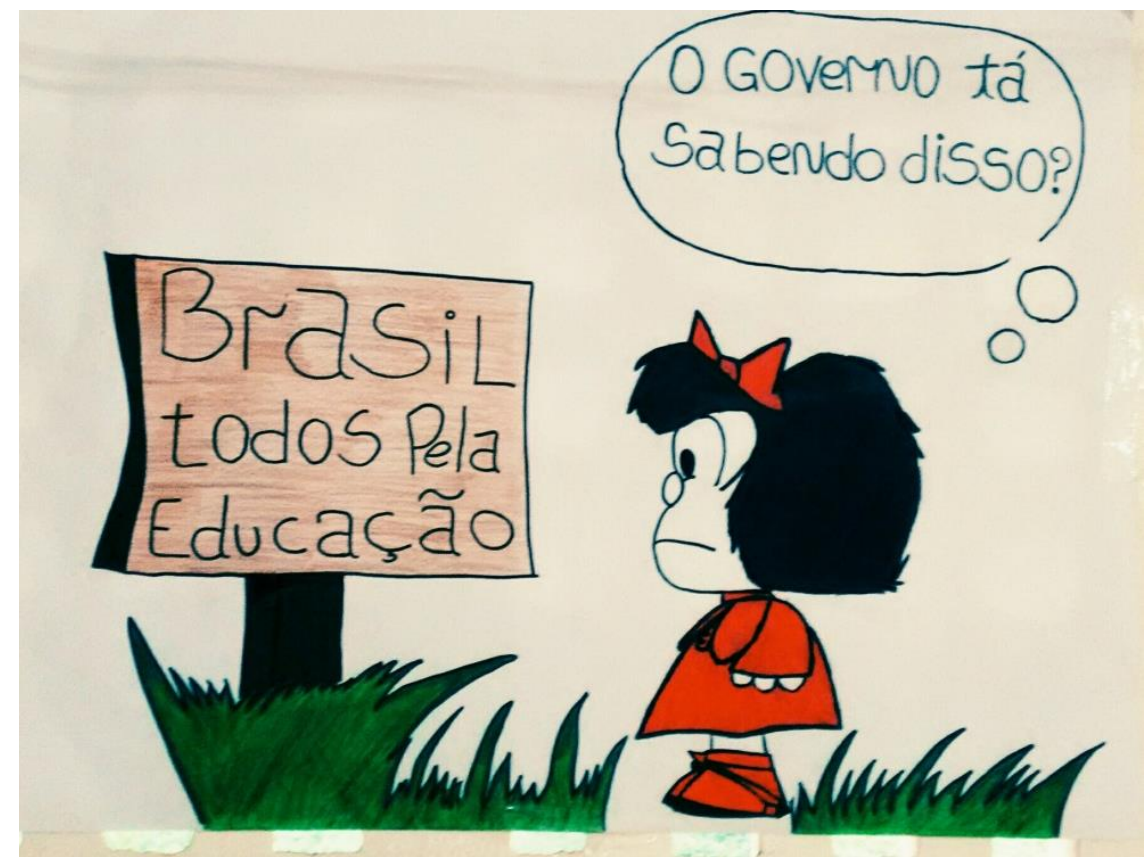

Fonte: acervo do autor

Figura 03 - Crise no ensino médio

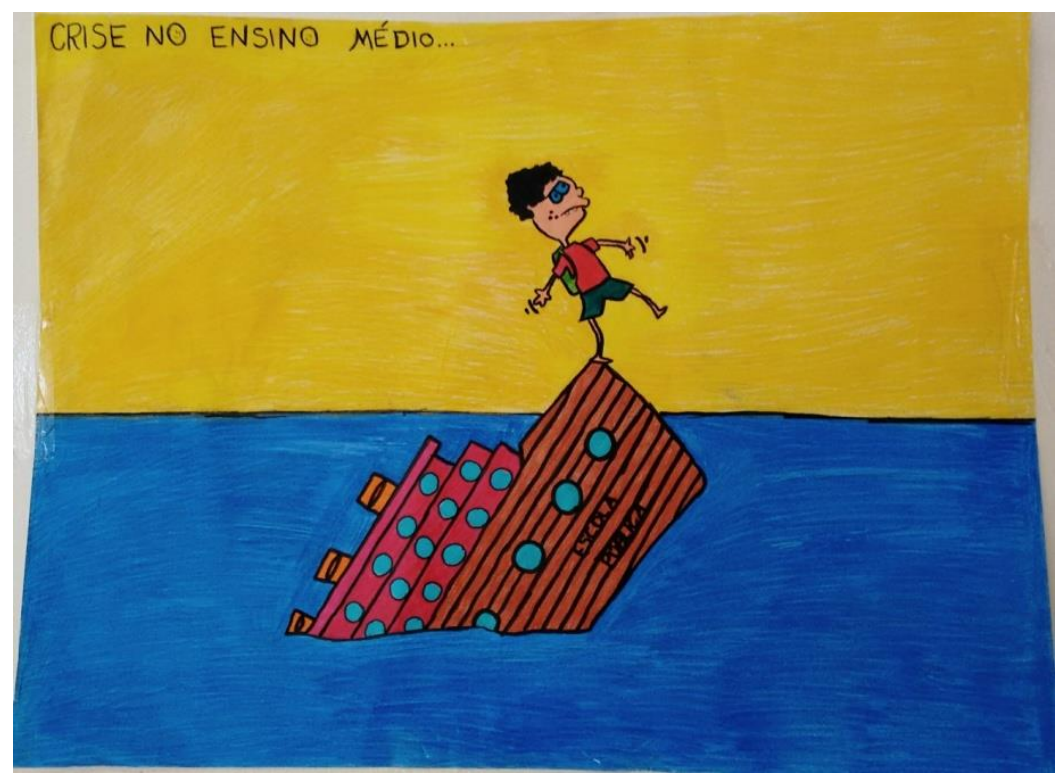

Fonte: acervo do autor. 
Praticando a Interdisciplinaridade no Ensino de Geografia por Meio das Tiras em Quadrinhos...

Os próximos cartazes são tiras (figuras 04,05 e 06) que fazem alusão ao aquecimento global. Este tema gerou discussões profícuas a respeito do tema, já que os alunos ficaram divididos sobre o assunto. Alguns acreditavam na influência do homem no aquecimento global, já a outra parcela não aceitavam essa teoria. Talvez esse confronto de ideias fizeram muitos alunos optarem por cartuns sobre esta temática.

Figura 03 - Polo Norte em 2100

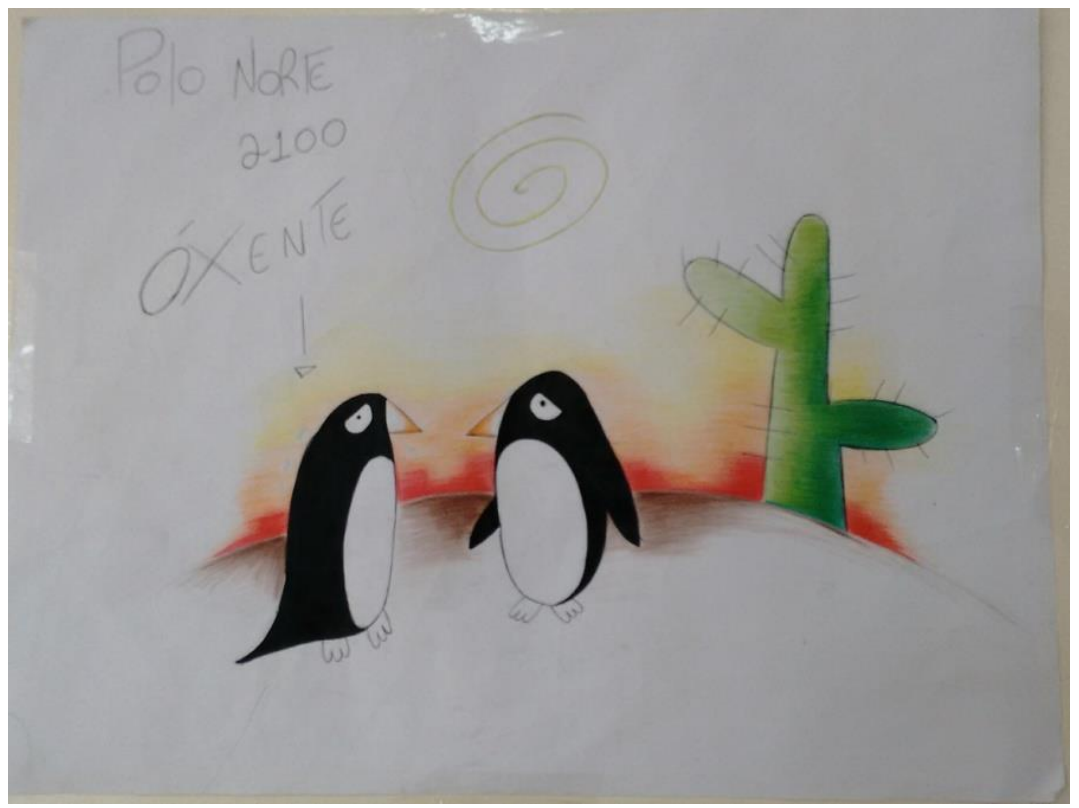

Fonte: acervo do autor

Um grupo aproveitou para se aprofundar ainda mais sobre o tema do aquecimento global e antes de elaborar a interpretação do cartaz da figura 03, os alunos fizeram uma história entre os pinguins, falando sobre o aquecimento do Planeta Terra (figura 04). Isso demonstra a criatividade dos alunos, pois foram além da atividade proposta e nos fizeram repensar a prática para a próxima oportunidade.

Analisando o diálogo (figura 04) é possível identificar informações que foram extraídas do texto jornalístico para elaborar o diálogo, como a previsão que o IPCC (Painel Intergovernamental sobre Mudanças Climáticas) faz sobre o aumento da temperatura na Terra. Já na interpretação do cartum os alunos fizeram uma comparação entre o polo norte e o nordeste, demonstrando a capacidade de compreender o regionalismo presente no cartum expressa pela palavra "oxente".

Nas figuras 05, 06 e 07 o alerta dos alunos foi à importância das regiões polares para a vida marinha. Sem a possibilidade de um ambiente adequado para os animais que vivem nas regiões polares não é possível sua sobrevivência. Nesse contexto, é possível introduzir 
temas importantes para compreender a geopolítica mundial como a preservação da Antártida a partir do Protocolo sobre Proteção Ambiental ao Tratado Antártico, conhecido como Protocolo de Madri, assinado em 1991 que traz como objetivo principal transformar a Antártica um santuário ecológico, buscando o impacto ambiental zero das atividades humanas.

Figura 04 - História criada pelos alunos para a tira e a sua interpretação.

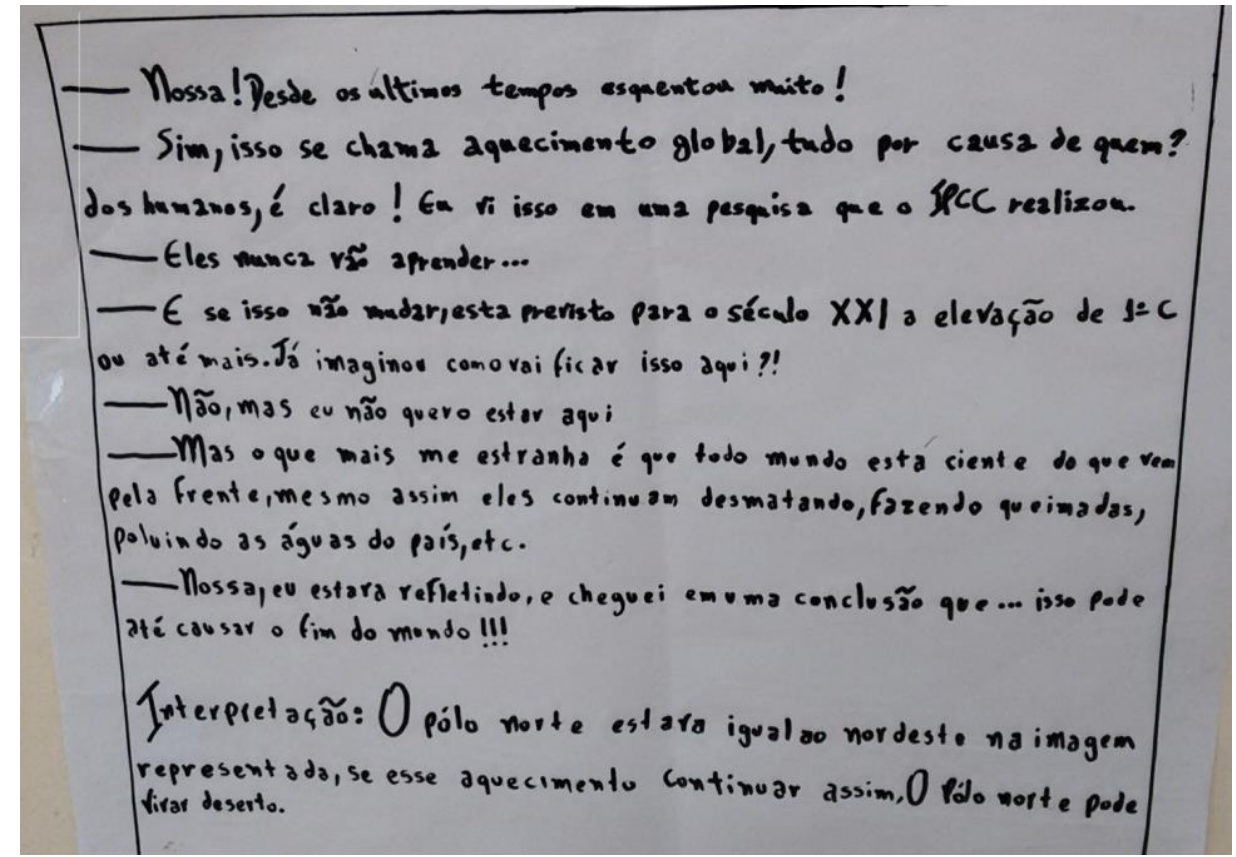

Fonte: acervo do autor.

Figura 05 - Tira fazendo alusão ao aquecimento global

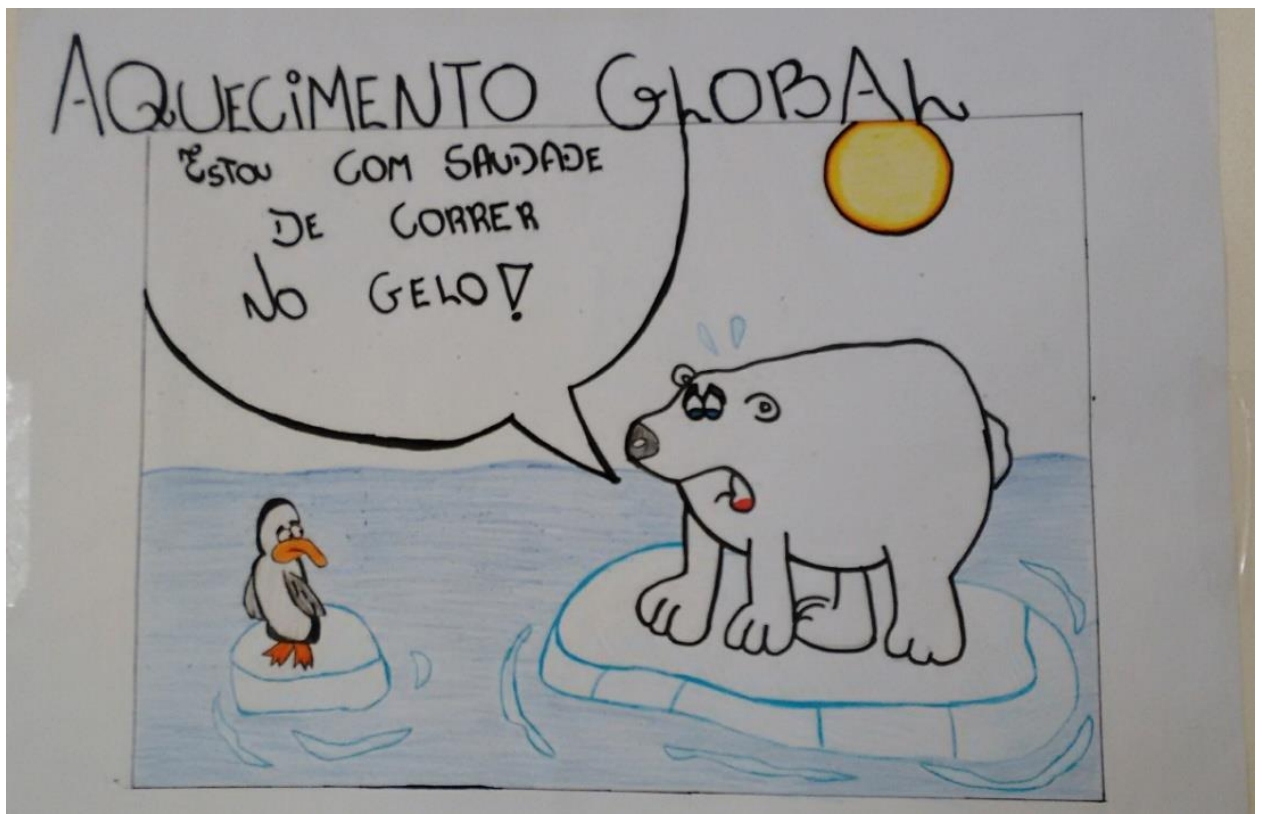

Fonte: acervo do autor

Geografia (Londrina) v. 26. nº. 2. p. $128-144$, jul/dez, 2017. 
Praticando a Interdisciplinaridade no Ensino de Geografia por Meio das Tiras em Quadrinhos...

Figura 06 - Interpretação da charge da figura 05

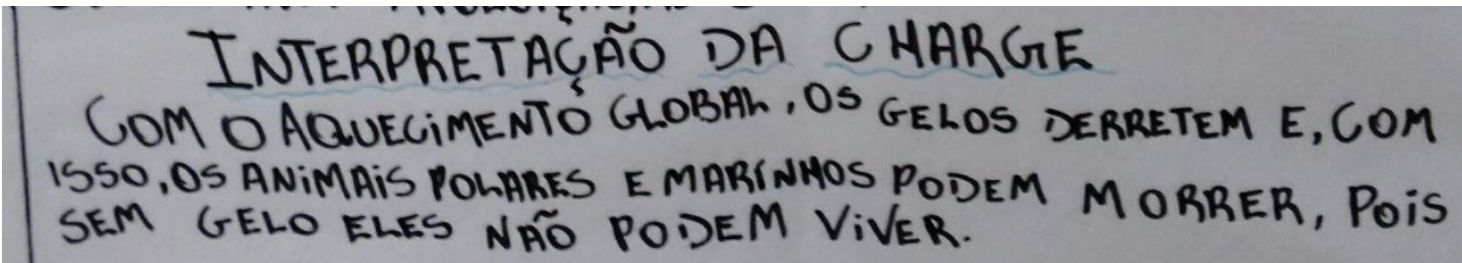

Figura 07 - "Pai, existiu mesmo gelo?"

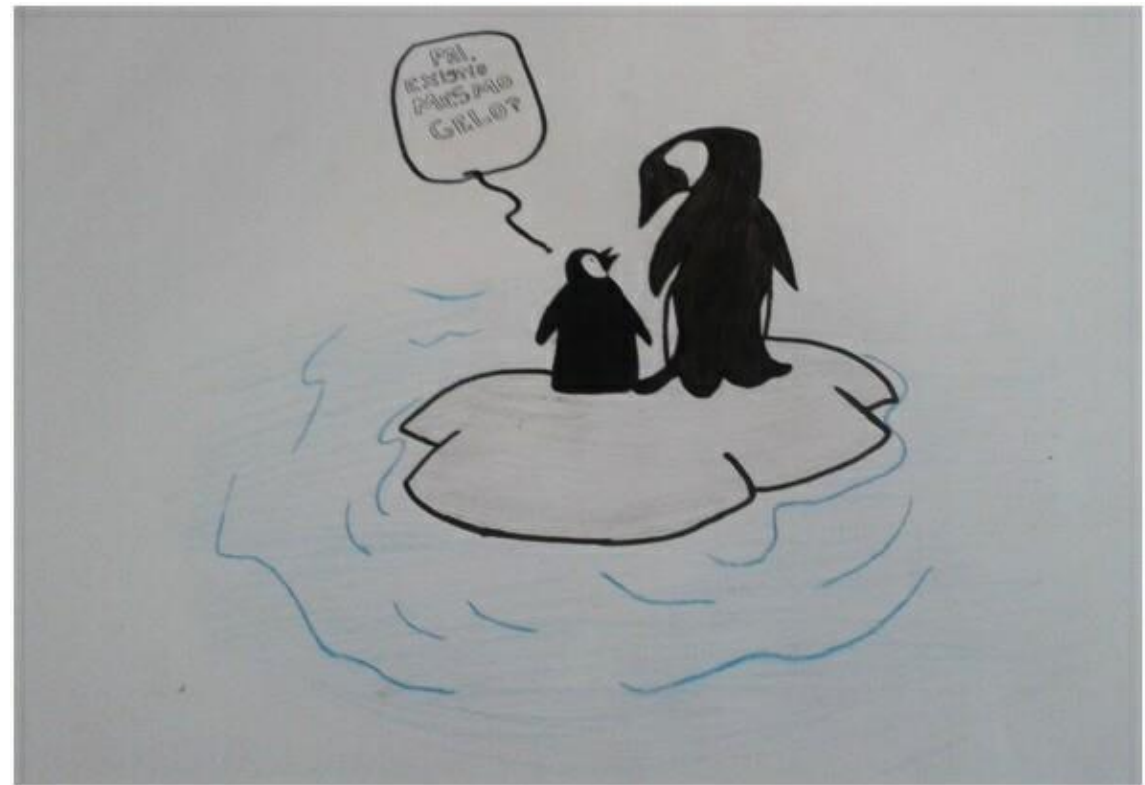

Fonte: acervo do autor

Os próximos cartazes (figuras 08 e 09) apresentam como tema principal a desigualdade social, mostrando os contrastes entre as classes sociais. Na figura 08 , a tira faz uma sátira com o Iphone, objeto de desejo de muitos jovens atualmente, evidenciando a realidade da desigualdade social no mundo. A partir do tema foi possível trabalhar com os alunos efeitos da globalização na sociedade e o aumento do consumo, tornando possível relacionar o cartaz confeccionado pelos alunos e a fabricação de mercadorias das empresas transnacionais em países subdesenvolvidos.

O quadro da desigualdade no mundo só aumenta. Em um pesquisa divulgada este ano pela organização não-governamental britânica Oxfam (2016), demonstra que até o final deste ano, a riqueza de $1 \%$ das pessoas mais ricas do planeta deve ultrapassar a dos outros $99 \%$ da população.

Já a figura 09, além da desigualdade social, reflete também outro problema das nossas cidades brasileiras: crianças no semáforo pedindo ajuda aos motoristas. Muitos 
Vitor Ferreira de Souza \& Drielle Caroline Izaias Juvino Souza

jovens ainda não frequentam as escolas e têm que trabalhar desde cedo para complementar a renda da família.

Figura 08 - O Iphone: objeto de desejo dos jovens.

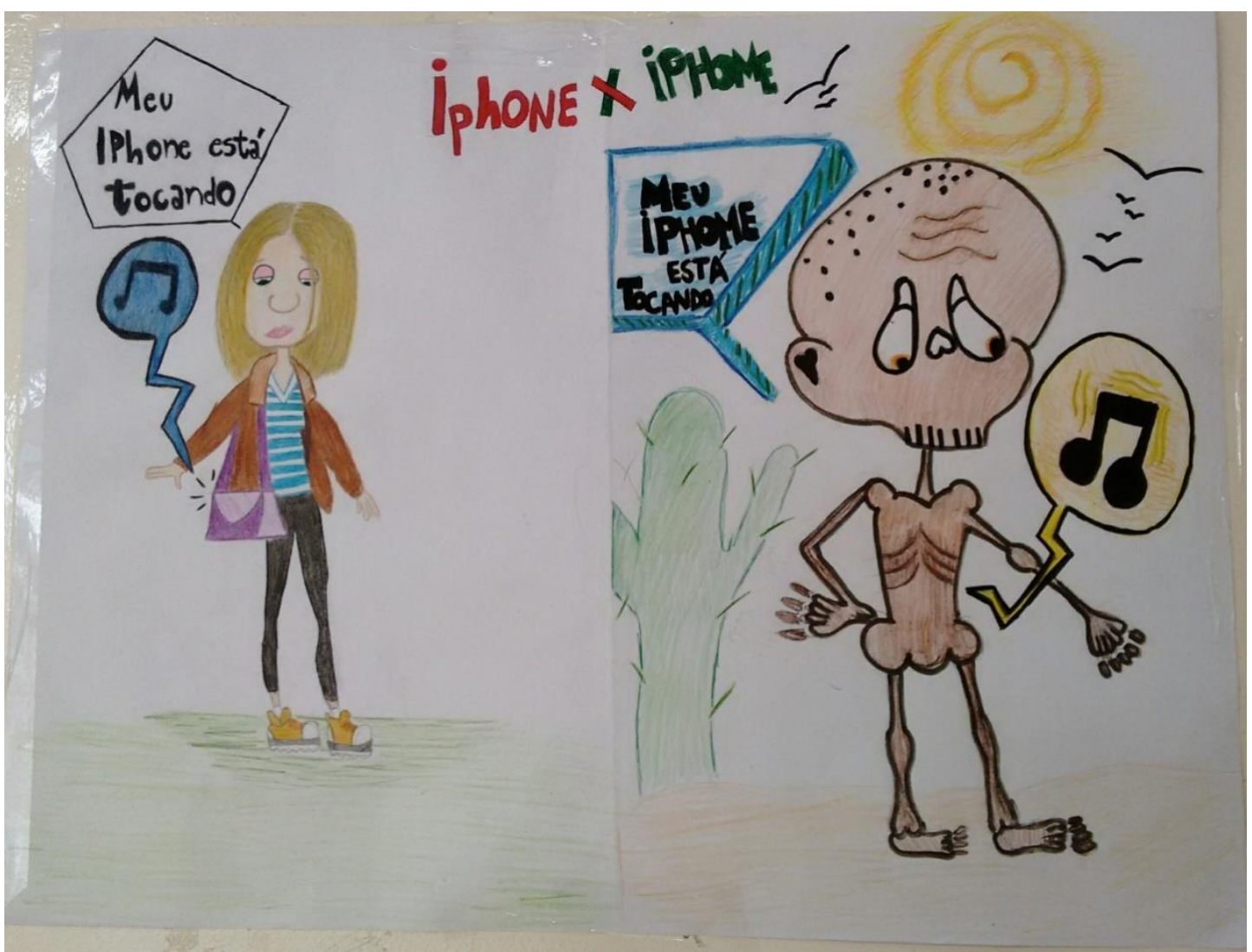

Fonte: acervo do autor

Figura 09 - Desigualdade social

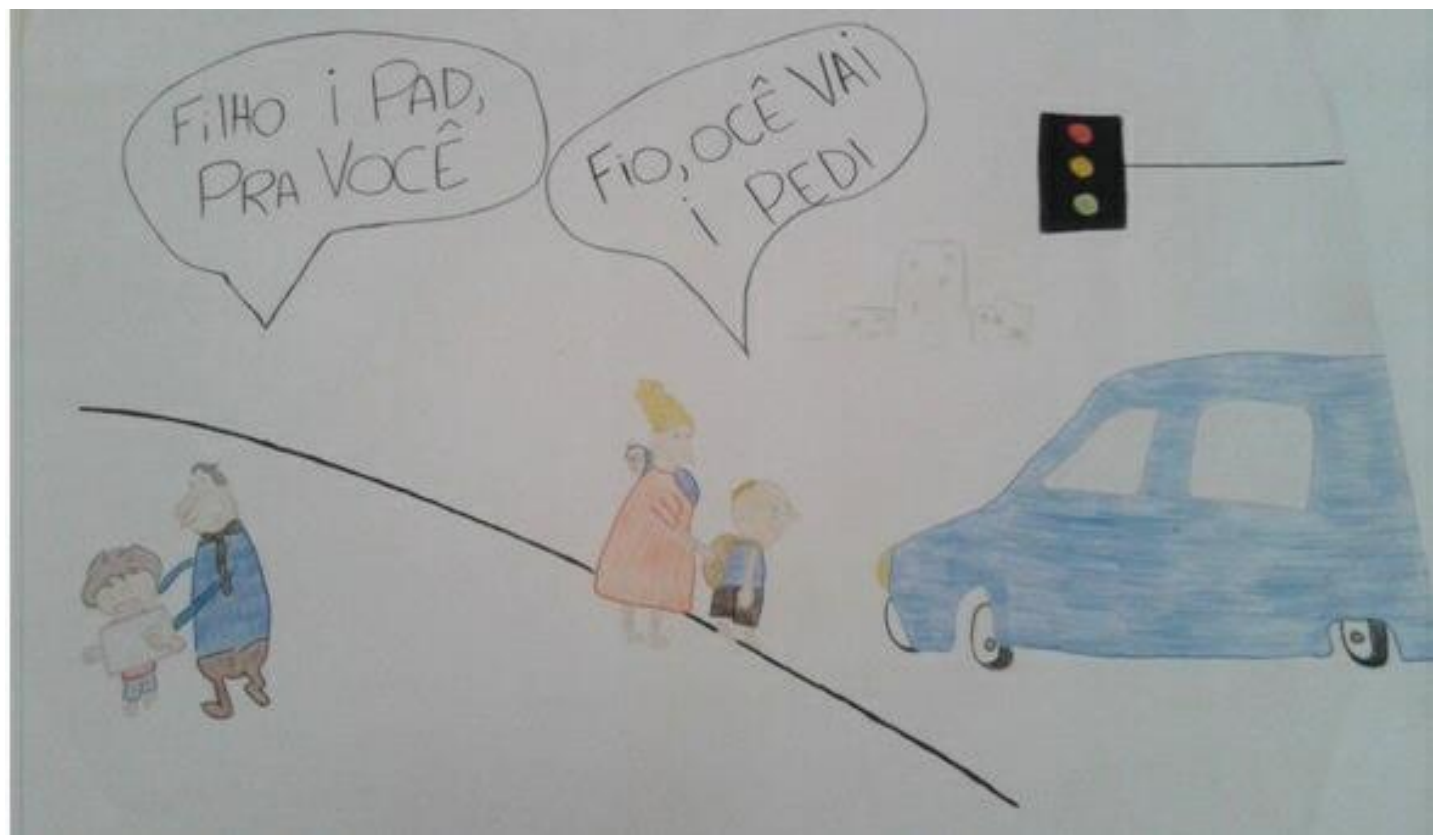

Geografia (Londrina) v. 26. nº. 2. p. $128-144$, jul/dez, 2017. 
Praticando a Interdisciplinaridade no Ensino de Geografia por Meio das Tiras em Quadrinhos...

Fonte: acervo do autor

Na figura 10, o grupo de alunos abordou a questão da renda para garantir acesso às condições básicas de vida, além do alerta que fazem quando ressaltam que a renda não é tudo. A partir desse cartum é possível fazer uma comparação das oportunidades que as diferentes classes sociais no país possuem e a importância das políticas públicas para a minimização de dos problemas da desigualdade social.

É importante salientar que a desigualdade social é um fator crucial para se compreender a configuração espacial de nossas cidades, já que elas nada mais são que retalhos de várias realidades ali presentes (LEFBVRE, 2000). É na cidade que se expressa a desigualdade social nas paisagens, com lugares voltados para a classe alta e outros lugares segregados para os pobres.

Lefbvre (2000, p.154) ressalta que essa desigualdade social produz a fragmentação do espaço, separando os ricos dos pobres, dessa forma as funções das cidades também acabam se parcelando: trabalho, moradia, lazeres, transportes, produção e consumo. "[...] 0 espaço - como o trabalho - se torna parcelado: justaposição de parcelas fixadas a uma atividade parcial, no qual o conjunto, o processo de habitar escapa aos participantes".

Figura 10 - Interpretação do cartaz da figura 09

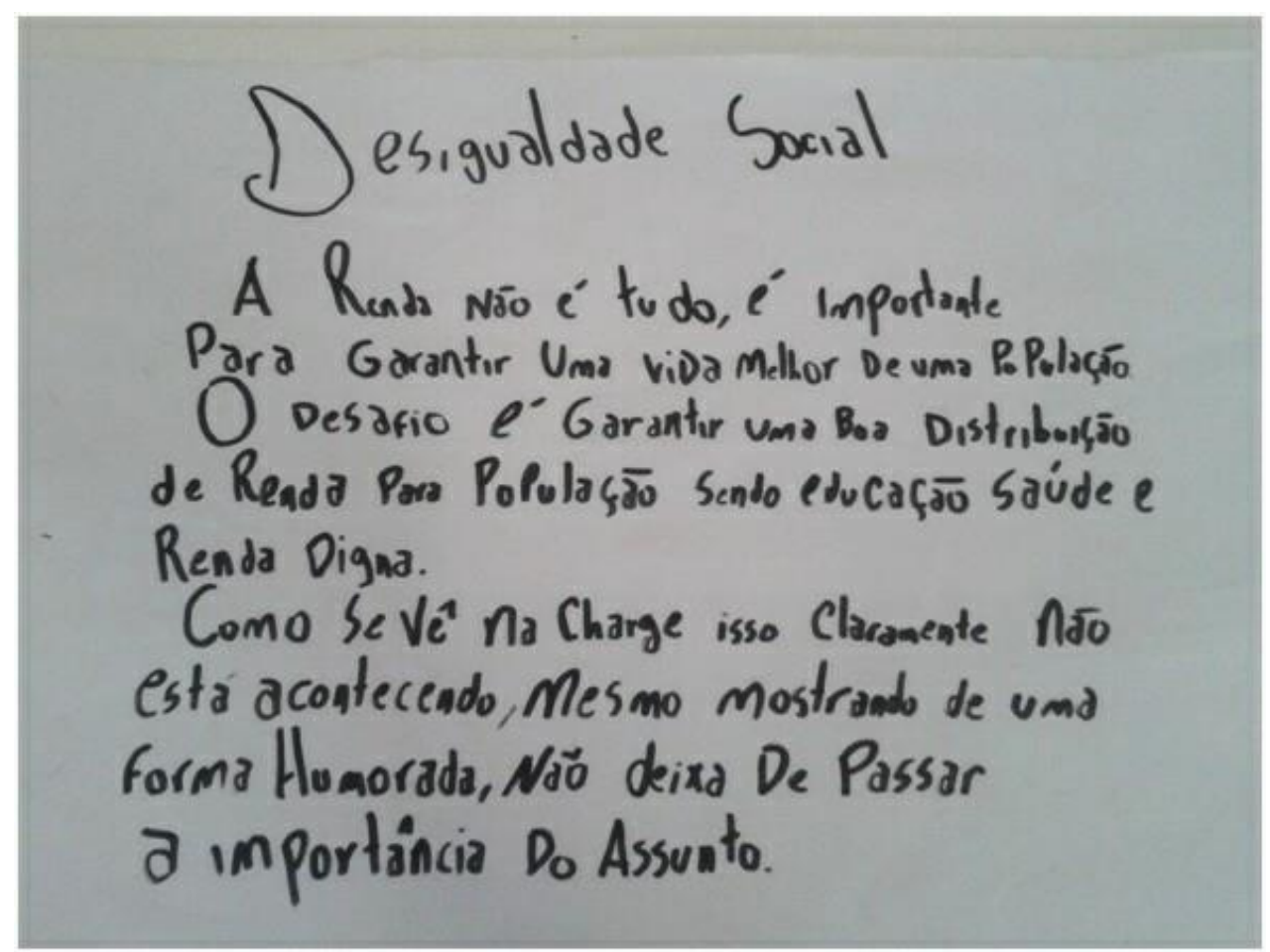

Fonte: acervo do autor

Geografia (Londrina) v. 26. nº. 2. p. $128-144$, jul/dez, 2017. 


\section{CONSIDERAÇÕES FINAIS}

Como se pode notar pelos cartazes, tanto a atividade para o ensino de geografia quanto para o de língua portuguesa contribuíram para explorarmos diversas habilidades dos alunos, entre elas a escrita, interpretação, síntese, desenho, entre outras. Mesmo com algumas adaptações ao longo do caminho, a proposta serviu para refletirmos sobre a nossa prática.

Observamos na prática que a busca pela interdisciplinaridade ainda é um desafio para nós, os docentes, pois é difícil obtermos ideias que contribuam para uma aproximação entre as disciplinas. Vale lembrar que práticas como esta podem ser expandidas para as demais matérias escolares.

Devemos ressaltar o papel fundamental da direção da escola para a prática fazer valer, já que muitas vezes o trabalho era realizado com as duas turmas em conjunto com os professores de língua portuguesa e geografia auxiliando na proposta. Essa questão evidencia a importância de toda a escola se adequar para a busca do trabalho em conjunto.

Em específico sobre a disciplina de geografia, notou-se uma melhora na internalização dos conteúdos trabalhados e o surgimento de novas discussões, além da maior abertura para os alunos falarem sobre os problemas que as tiras e os cartuns abordavam.

Esperávamos que os alunos modificassem as tiras e cartuns de acordo com a realidade que vivenciam em seus bairros. No entanto, isso não ocorreu. As modificações foram superficiais, mantendo a proposta inicial do recurso didático.

$\mathrm{Na}$ área da Língua Portuguesa, a contribuição específica consistiu no contato com os gêneros textuais em questão, além do trabalho com interpretação e produção de textos. Os alunos puderam realizar a leitura de textos verbais e não verbais através de textos informativos, tiras, charges e cartuns. A partir dessas leituras, desenvolveram algumas habilidades referentes à: interpretação de texto, identificação e seleção das ideias principais de textos informativos e produção textual. Além disso, os textos produzidos pelos alunos passaram por algumas etapas de correção ortográfica para a elaboração dos cartazes.

Cremos que o trabalho interdisciplinar foi relevante ao passo que permitiu a reflexão e apropriação de conteúdos relacionados ao espaço geográfico em consonância com aspectos envolvendo interpretação e produção de textos. 
Praticando a Interdisciplinaridade no Ensino de Geografia por Meio das Tiras em Quadrinhos...

Com isso, desejamos a todos os professores que se aventurem em novas práticas pedagógicas, mesmo com as dificuldades encontradas ao longo do caminho docente. A renovação da prática não se reflete apenas nos alunos, mas também no docente.

\section{REFERÊNCIAS}

BRIDON, J. Entre um texto e outro, o leitor em formação. 2013. 161f. Dissertação de Mestrado. Univali, Itajaí, 2013.

CORRÊA, R. L. Região: a tradição geográfica. In: Trajetórias geográficas. Rio de Janeiro: Bertrand Brasil, 2001. p. 23-45.

FAZENDA, I. C. A. Interdisciplinaridade: história, teoria e pesquisa. 10 ed. Campinas: Papirus, 2008.

INSTITUTO PAULO MONTENEGRO (IPM). Instituto Paulo Montenegro e Ação educativa mostram evolução do alfabetismo funcional na última década. Disponível em: $<$ http://www.ipm.org.br/ipmb_pagina.php?mpg=4.03.00.00.00\&ver=por>. Acesso em 26 de jan. 2016.

JAPIASSU, H. Interdisciplinaridade e patologia do saber. São Paulo: Imago, 1976.

KLEIMAN, A. B.; MORAES; S. E. Leitura e interdisciplinaridade: tecendo redes nos projetos da escola. Campinas: Mercado das Letras, 2002.

LEFEBVRE, H. La production de l'espace. Paris: Anthropos, 2000.

MENDONÇA, M. R. de S. Um gênero quadro a quadro: história em quadrinhos. In: Gêneros textuais e Ensino. Rio de Janeiro, Lucerna: 2001.

MORETTI, F. Qual a diferença entre charge, Cartum e quadrinhos? Disponível em: $<$ http://ccghumor.com.br >. Acesso em 20 de jan. de 2016.

MORIN, E. A cabeça bem-feita: repensar a reforma. Reformar o pensamento. Tradução: Eloá Jacobina. 21. ed. Rio de Janeiro: Bertrand Brasil, 2014.

OXFAM. An economy for the 1\%. Disponível em: <http://www.oxfamamerica.org/static/media/files/bp210-economy-one-percent-tax-havens-

180116-en_0.pdf>. Acesso em 26 jan. 2016.

PUNTEL, G. A. A Paisagem no ensino da Geografia. Ágora. Santa Cruz do Sul, v. 13, n. 1, p. 283-298, jan/jun. 2007.

SANTOMÉ, J. T. Globalização e interdisciplinaridade: o currículo integrado. Porto Alegre: Artmed, 1998.

SILVA, C.L.M. 0 trabalho com charges na sala de aula. Disponível em :<http://www.unisc.br/portal/images/stories/mestrado/letras/coloquios/ii/charges_sala-deaula.pdf>. Acesso em 23 maio. 2016.

SILVA, E. I. da; CAVALCANTI L. de S. A mediação do ensino aprendizagem de geografia, por charges, cartuns e tiras de quadrinhos. Boletim Goiano Geografia, no. 2. Goiana (GO): AGB, 2008, p.141 - 156. 
1 Formado em Geografia pela Universidade Estadual de Londrina - UEL, Professor efetivo de geografia, Prefeitura Municipal de São José do Rio Preto, Rua São José, Centro n2374 - Centro - Mirassol, Email: vitorfssouza@gmail.com

2 Formada em Letras e Inglês pela Universidade Federal de São Carlos - UFSCar, Mestre em Linguística Aplicada pela UFSCar, Professora efetiva de inglês, Prefeitura Municipal de São José do Rio Preto, Av. José da Silva Sé, 405 - Casa 115 - São José do Rio Preto, Email: drielle.cii@gmail.com 